\title{
TBLT in Asia: Constraints and Opportunities
}

\author{
Rebecca Adams \\ University of Auckland \\ Jonathan Newton \\ Victoria University of Wellington
}

\begin{abstract}
Task-based language teaching (TBLT) has been adopted by several Asian governments as the national approach to English language pedagogy, and principles associated with task-based teaching have been advocated in a range of other curriculum initiatives. However, large scale top-down curricular revisions may not directly impact actual language teaching practice. In this article, a brief description of curricular innovation and curriculum dissemination, as well as an overview of task-based teaching is provided. This is followed by a discussion of institutional, classroom, and teacher development constraints that may limit the implementation of TBLT in Asian English language teaching. Despite these challenges, emerging evidence of successful, grass-roots implementation of task-based teaching in Asia points to opportunities for further adoption - and adaptation - of taskbased English language teaching in Asian educational settings.
\end{abstract}

\section{TBLT and Asian Educational Policy}

In many Asian countries educational policies and national curricula devised for English language teaching in the past ten years have adopted communicative and taskbased language teaching (TBLT). National curricula and Ministry of Education policies in countries including China (Hu, 2005; Zhang, 2007), Taiwan (Sung, 2005), and Hong Kong (Carless, 2007) all specify that task-based approaches to teaching English should be used at all levels of the curricula, while in other areas, including South Korea (Shim \& Baik, 2000) and Japan (Hood, Elwood and Falout, this volume) education policies require teachers to adopt a communicative approach to English language teaching, and indicate that classroom tasks may be used as a means of achieving meaningful classroom language practice. In addition, TBLT is currently being introduced throughout Asia through smaller scale initiatives at institutional and classroom levels, as for example in Thailand (McDonough \& Chaikitmongkol, 2007), Korea (Finch, 2001), and Japan (O'Dwyer, 2009). Recent curricular planning in Asia has included principles such as teaching that promotes learner-centeredness, comprehension and communication, and understanding foreign cultures (e.g., $\mathrm{Hu}$, 
2005; Shim \& Baik, 2000), a focus on communicative competence, developing language learning strategies, and fostering autonomy (e.g., Sung, 2005).

While educational policy in Asia heavily favours TBLT and other communicative, holistic approaches to language teaching, a large body of classroom-based research on current teaching in Asia indicates that these policies have not always been implemented thoroughly or consistently. Research conducted across East Asian contexts has overwhelmingly suggested that curricular policies have had limited overall impact on English language teaching, which remains traditional with an explicit grammar-teaching focus (e.g., Carless, 2007; Hu, 2005; Zhang, 2007). Current research by Deng \& Carless (this volume) and by Luk (this volume) echo earlier findings that curricular policies promoting the use of TBLT at the national level do not automatically translate into the use of TBLT in actual English language classrooms.

Why is there a gap between government curricular innovations and the practice in actual classrooms? Adamson and Davison (2003) point out that in the case of topdown curricular innovation, stakeholders including schools and teachers can choose several different types of responses, ranging from explicit rejection of the innovation (in this case TBLT) to 'creative co-construction' in which the stakeholders adopt and localize the principle elements of the innovation. Between these two ends of the spectrum are differing degrees of compliance with the innovation. While schools and teachers may not explicitly reject government level policies, they may nevertheless choose to minimally adopt selective elements of the innovation, with relatively little change to their current pedagogical practices. Decisions about whether and how to adopt curricular innovations must be made at several levels, as summarised in Zhang's (2007) revision of Adamson and Davison's (2003) model of curricular decision making, reproduced below.

Figure 1. Stages in top-down curriculum decision-making (reproduced from Zhang, 2007).
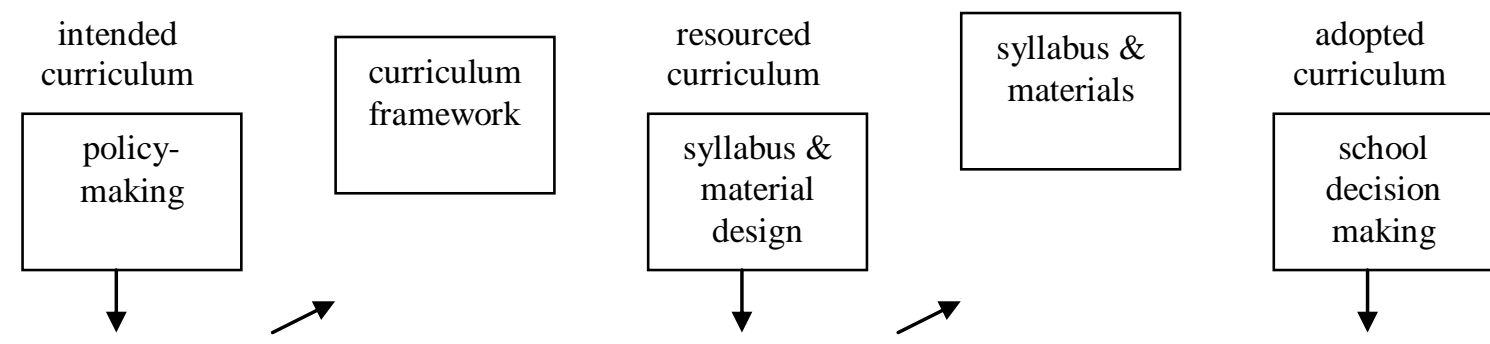


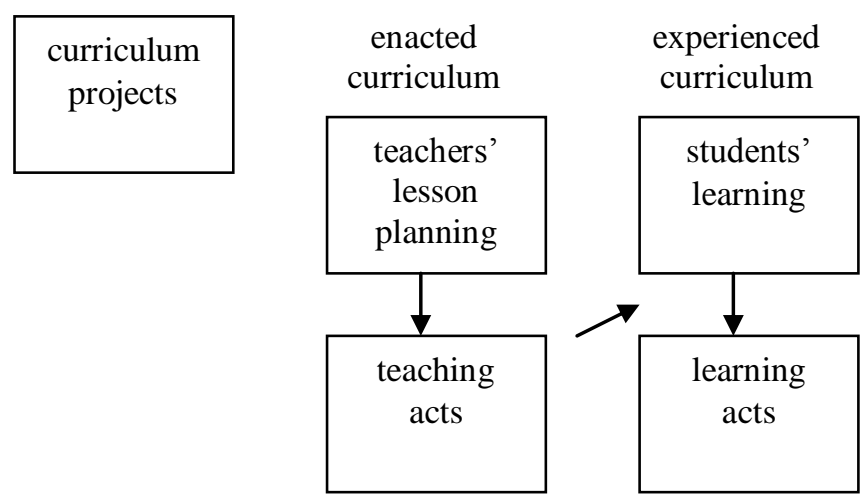

As the model indicates, curriculum planning requires interaction between different stakeholders at different levels. As Adamson and Davison (2003) point out, at each of stage of this process, the innovation must be reinterpreted by different stakeholders. Because of this chain of interpretations, top-down curricular innovations may be disseminated in a form substantially different to what was originally envisioned (Kelly, 2004; Zhang, 2007). In Zhang's study, for example, decentralization of the bodies responsible for the resourced curriculum led to different interpretations of the role of TBLT in the curriculum, as well as "limited, sporadic, unsystematic, and sometimes contradictory dissemination of TBLT by various disseminators, including educational authorities, teacher trainers, university scholars, and textbook writers" (p. 76).

Further, at the level of the adoption of the curriculum by schools, Zhang found quite superficial efforts to adopt the curriculum, with little commitment to creating a supportive environment for teachers to experiment with new means of classroom practice. At the level of the enacted curriculum, Adamson \& Davison (2003) describe overall very minimal adoption of the task-based Hong Kong Target Oriented Curriculum by teachers and schools, with teachers struggling to make sense of the curriculum, and eventually returning to traditional means of teaching. At the level of the experienced curriculum, Adamson \& Davison (2003) also noted doubts expressed by students about the effectiveness of curricular innovations in Hong Kong, which may have been influenced by conservative parental beliefs about education. Zhang (2007) notes that, because TBLT was weakly implemented in the Chinese schools she investigated, student educational experiences most closely matched their teacher's language teaching beliefs, not the top-down prescribed curriculum. Overall, studies of TBLT curricula in East Asian English language teaching have shown minimal adoption of the curriculum at all levels of curricular decision-making. In order to 
contextualize these findings as well as the studies of this special issue, the following two sections will focus on first a description of tasks in language learning and teaching, and second a discussion of factors that have limited the implementation of TBLT in Asian contexts. The final section provides an introduction to the studies in this special edition, which focus on the enactment and experience of TBLT in different Asian contexts.

\section{What is Task-Based Language Teaching?}

Definitions of tasks vary, but core concepts from most definitions are captured by Samuda and Bygate's (2008) recent discussion of tasks, which they define as:

A task is a holistic activity which engages language use in order to achieve some non-linguistic outcome while meeting a linguistic challenge, with the overall aim of promoting language learning, through process or product or both (p. 69).

Tasks form the focus of TBLT. In a task-based course then, the emphasis is on meaningful, holistic language practice, in which learners need to listen, read, speak, or write in order to complete a challenge. The rationale for TBLT as a teaching approach is found in theories of language acquisition that emphasise the central role in language learning of meaningful language use allied with opportunities to notice ways in meanings are created through the target language (e.g. Long, 1996; Skehan, 1998). According to such theories, opportunities for communicative use and noticing form/meaning/function relationships provide the conditions under which communicative competence in a second language can most effectively be developed (Willis \& Willis, 2007).

Translated into classroom practice, TBLT appears in both weak and strong versions. Weak versions, or what Ellis (2003) refers to as "task-supported language teaching", use tasks for communicative practise but in other respects follow a conventional grammar or function-based syllabus. Strong versions, referred to by Ellis as "task-based language teaching", treat the task as the central unit of curriculum and lesson planning. The tendency for teachers to translate officially mandated TBLT into what at best could be called task-supported language teaching is a theme addressed in a number of places in this collection. 
Interest in tasks in language teaching has gathered pace over the past decade as seen in rapidly expanding number of authored books and edited collections on TBLT (e.g. Bygate, Skehan \& Swain, 2001; Ellis, 2003 \& 2005; Nunan. 2004; Samuda \& Bygate, 2008; Van den Branden, 2006; Willis \& Willis, 2007) and in the biannual TBLT Conference $(2005,2007 \& 2009)$ dedicated to furthering research on tasks in language teaching. The adoption of tasks as a basis for communicative language practice and a means of language instruction in curricular planning in Asia and elsewhere is an indication of the increasing influence of tasks on language teaching.

\section{Challenges for Adopting TBLT in Asia}

A large body of research has investigated the difficulties associated with implementing TBLT in East Asian contexts. Because full accounting of these factors is beyond the scope of this introductory article, we will focus on three types of factors that have been commonly reported as difficulties in implementing TBLT and other communicative language teaching approaches: factors related to the institutional culture, factors related to classroom teaching, and factors related to teacher development.

\section{Institutional Factors}

As Zhang (2007) points out, in order for tasks to be enacted by teachers in the classroom, the government institutions that plan educational policy and the schools that adopt them need to create a supportive environment for teachers to experiment with new teaching approaches in their classrooms. At the governmental level, the measurement of success in language teaching and learning through norm-referenced, knowledge-based, vocabulary- and grammar-focused exams may hinder efforts to use task-based teaching in the classroom. Hu (2002) has indicated that national level grammar and vocabulary knowledge-focused national exams is one of the most influential factors preventing teaching innovation in China. Chow \& Cheung (2004) consider the summative, knowledge-based high stakes exams used in Hong Kong to be the main barrier to implementing TBLT. Shim \& Biak (2000) point out that curricular communicative objectives are not reflected in the Korean national exams, so washback from the exam pressures teachers to revert to traditional, rote-learning approaches to teach to the test (e.g., Li, 1998), and similar concerns have been noted by Japanese teachers and students (e.g., Gorush, 2000). External examinations can 
limit the implementation of TBLT because the largely multiple choice testing formats lead administrators and teacher to prefer explicit teaching approaches (e.g., Carless, 2007; Littlewood, 2007).

These concerns with the effect of high-stakes national examinations on learning are also echoed by Deng \& Carless (this issue), who found that their case study teacher, Rose, was reluctant to integrate communicative activities into her classroom, concerned that her students needed more mechanical practice to prepare them for the national exams through which the students, the teacher, and the school are all judged. It is important to remember, however, that while the nature of EFL examinations in many countries may not foster support for curricular changes, simply integrating communicative and skills-based testing into exams will not guarantee enactment of tasks in language classrooms. As Carless (2007) points out, teachers may still consider traditional methods of teaching as more appropriate, regardless of the manner of testing.

As well as national educational policies, institutional cultures of individual schools may foster or inhibit the adoption of task-based curricula. Zheng (2007) points out that without institutional support, including sustained teacher education on curricular innovations, teachers can be left with instructions to use methods they do not fully understand. The nature of institutional support may also be quite important. Zheng found, for example, that many schools in Guangdong Province made use of the new curriculum as a marketing tool, claiming to be following innovations while making few or no changes to the actual teaching facilities and offering minimal teacher education opportunities. Tinker-Sachs (2007) points out that teacher development initiatives need to be sustained over time to influence teaching practice. In addition, common school-based development activities like peer observation and feedback may not be likely to promote changes from the status quo. In Deng and Carless (this issue), the case study focus teacher was criticised by her colleagues after a peer observation for using a more task-like activity in the classroom. Some of her peers considered it too risky to allow the students to use new language, and indicated that the teacher should instead have provided model sentences.

As discussed above, the curricular move to TBLT in Asia has largely been a topdown process. For this to be successful, considerably more attention may be needed at both the policy-making and school decision-making levels to foster an environment where experimentation is welcomed. Additionally, factors associated with the enacted 
curriculum (the level of teacher decision-making) will need to be addressed. These include both factors related to the classroom environment and factors relating to teacher development.

\section{Classroom Factors}

The set-up of many English language classes in Asia, particularly at public secondary schools, is not conducive to the use of tasks in class. A frequently mentioned concern is large class sizes, which have been noted as a barrier to change in Korean (e.g., Jeon, 2006; Li, 1998), Hong Kong (e.g., Carless, 2002), and Chinese (e.g., Zhang, 2007) schools. Li (1998) points out that large classes are inherently difficult to manage, and thus challenge teacher ability to make changes to their teaching. Littlewood (2007) has noted that it is particularly difficult to implement TBLT in large classes because of logistical issues associated with students communicating in groups. It should be noted, however, that many of the issues associated with large classes are relevant only to the use of interactive pair- or small group-tasks. The logistics associated with tasks targeted at listening or reading comprehension, or at written production, may not be as strongly constrained by class size.

A related issue to class size is the presence of students with multiple ability levels in each class. Because primary and secondary students may be streamed by age rather than proficiency, mixed proficiency classes are common in Asian contexts (e.g., Butler, 2005). Chao and $\mathrm{Wu}$ (2008) point out that the inclusion of students at a range of proficiency levels in Taiwanese schools makes it difficult for teachers to select appropriate tasks for their classes. To address this issue, Tinker-Sachs (2007) proposes promoting cooperative learning, whereby students of different proficiency levels can help one another.

As noted previously, large, mixed-proficiency classes can be quite unwieldy, and Asian teachers have traditionally relied on a strong teacher-fronted information transfer model of teaching to maintain classroom order (Cortazzi \& Jin 2001). Good classroom management is often defined in terms of volume, with students individually working quietly and not causing disruption (Cortazzi \& Jin, 1996). Because taskbased approaches call for a range of participatory structures (e.g., whole class, small group, pair, individual, c.f., Ellis, 2003), TBLT challenges traditional views of classroom management. Jean (2006) noted that very few of the Korean EFL teachers 
in her sample considered TBLT as an appropriate way to manage the classroom. Carless (2004) suggests that teachers may struggle with the noise generated by pairand group-work, and that they may need to learn to separate the noise of students engaged in using language to complete a task from the noise of classroom disorder. This clearly calls for a shift in perspective.

On the other hand, it is not only teachers that may need to adjust to the inclusion of group- and pair-work in task-based courses. Students accustomed to traditional methods, and particularly to methods that promote accuracy over fluency, may find it difficult to use English in the classroom. Li (1998) has found that Korean students resist oral class participation, while Eguchi \& Eguchi (2006) noted that their students were reluctant to use English productively during communicative class work, choosing instead to use Japanese even for simple communication and utterances they were familiar with in English. They speculate that this may have limited the learning potential of a task-based course. Chang's survey of native speaker English teachers in Korea indicated that they considered their students overly reliant on authority figures and reluctant to take risks through speaking. When students can be motivated to speak in English, they may produce the simplest language possible, attending not to stretching their linguistic resources and developing compensatory strategies, but rather to avoiding mistakes to save face (Lee, 2005). Learner reluctance to speak in class may then undercut the value of interactive and production tasks for language development.

However, there is also evidence that, once exposed to task-based teaching, Asian learners can adjust their preferences for learning. Zhang (2007) found that the students of the most communicatively-oriented teacher in her sample also preferred communicative teaching, felt that English should be used as much as possible in the classroom instruction, and tried to speak English as much as possible. Hsu (2007) found that Taiwanese students who had been exposed to task-based teaching preferred group to individual work, and Tinker-Sachs (2007) found that the use of cooperative task-based learning in Chinese primary schools increased the amount of English used by both students and teachers in the classroom (see also Tinker-Sachs, this issue). Weaver (2007) found a strong effect of task-type on student willingness to communicate in English in a Japanese classrooms, indicating that promoting L2 use in the classroom may be successful when tasks that motivate learners are used. He also found that learners who had been exposed to TBLT for longer were more willing to 
use English in class, a finding echoed by Hood, et al.'s (this issue) analysis of tasks and learner motivation. These findings indicate that sustained exposure to TBLT may help overcome learner reticence to talk in the classroom.

\section{Tasks and Teacher Development}

Addressing concerns with integrating tasks into classrooms may help promote the enactment of TBLT curricula in Asian schools, but is unlikely to be successful unless it is accompanied by sustained teacher development initiatives. As Zhang (2007) noted, pseudo-compliance by schools in adopting task-based innovations has led to minimal teacher development efforts in China, while sustained, grounded, and culturally sensitive teacher development may be required for real change in the enacted curriculum (c.f., Carless, 2007). Because TBLT requires teachers to adapt materials and juggle classroom roles to serve the communication needs of their learners, using tasks effectively in the classroom requires understanding of the nature of tasks and the ways they can promote learning (Ellis, 2003). In many contexts, teachers have not had opportunities to gain sufficient understanding of tasks and taskbased teaching to be able to implement it in their own classrooms. Clark et al. (1999) identified vague understanding of TBLT as a main factor that limited the ability of Hong Kong teachers to implement the new curriculum, a finding echoed by Zhang (2007) for teachers in China and by Jeon (2006) and Butler (2005) for teachers in Korea. Carless (this issue) points out that even some of the teacher educators involved in promoting the Hong Kong task-based curriculum expressed uncertainty about the nature of tasks and about the effectiveness of holistic learning.

Similarly, teachers may feel uncomfortable with the shifts in teaching style required by TBLT. While critics of TBLT (cf. Sheen, 1994; Swan, 2005) have suggested that TBLT reduces the teacher role from teacher to facilitator, Samuda and Bygate (2008) point out that the role of facilitator may be much more complex than that of a knowledge transmitter, because of the need to be able to adjust plans as lessons unfold in response to learner communication and needs. This level of responsiveness is in many ways opposed to the 'authoritative' teacher persona considered ideal in Confucian philosophy (e.g., Carless, 2004; see also Jin \& Cortazzi, 1996 for discussion of the implications of Confucian heritage for language education). Teachers in Jeon's (2006) study considered demands to fill the role of facilitator so heavy as to constitute a psychological burden. As Carless (2007) suggests, TBLT may 
need to be culturally situated to accommodate local cultures in order to be accepted and enacted.

It is because of these challenges that teacher education which is limited to building teacher awareness and understanding of tasks and task-based teaching will not necessarily lead to enactment of TBLT in schools. Jeon (2006) points out that many of the Korean teachers in her study demonstrated understanding of tasks and teaching, but indicated that they were not in favour of implementing TBLT in their classrooms, for both logistic and acquisitional reasons. Logistically, they felt that tasks required too much preparation time and that the use of tasks would upset the management of their classrooms. In terms of acquisition, even among the teachers that used tasks, few considered them a means of increasing interlanguage competence. They were likely to consider tasks a way of motivating students, but not a means of promoting language learning. Simply legislating curricula will not cause real change in classrooms. For teacher development to successfully promote the use of tasks, teacher voices must be attended to.

One area of concern that teachers across contexts have raised in response to tasks is the demands on their own language proficiency. Several studies have indicated that teachers will avoid curricular innovations because they lack confidence in their own language proficiency, or because they consider English communicative practice the domain of native speaker English co-teachers (e.g., Butler, 2005; Jeon, 2006; Li, 1998; Shim, 2001). The practice of recruiting native speaker teachers to Korea and Japan may have the unintended consequence of creating a division between teaching the language and practicing the language, with regular classroom teachers concerned that the use of holistic activities is outside their domain and beyond their ability. It is possible that introducing comprehension-based tasks that do not place high production demands on teachers, and consciousness-raising tasks (c.f., Ellis, 2003) that privilege explicit knowledge of the language, may help teachers feel more comfortable using tasks in their teaching. Clearly, until teacher education promotes models of task-based teaching that teachers consider relevant to their learners and culturally acceptable for their teaching, little actual use of tasks in classrooms can be expected.

Overall, research on tasks in Asian English language teaching contexts has highlighted the challenges that language educators face in implementing TBLT. The purpose of this special addition is to present recent research which further investigates the challenges faced in implementing TBLT in Asia, how these challenges are 
experienced by teachers and students, and how they are responded to. A common theme is the tension between fidelity to the broadly accepted principles of TBLT and the need to accommodate to situational constraints. The way this tension plays out in the various settings described in this collection provides insights into the implementation of TBLT which have global currency and can contribute to greater understanding of TBLT in practice.

\section{Articles in the Current Issue}

The seven studies included in this collection share two common starting points tasks and an Asian English language teaching context. Each brings a unique perspective on these two points and contributes to a multifaceted view of TBLT in Asia. The studies report on tasks in language classrooms in primary, secondary and tertiary settings, and in four Asian countries: Hong Kong, Malaysia, China and Japan. They draw on a range of research methodologies including single case studies, a quantitative survey, qualitative interview data, and a quasi-experimental design. And finally, they investigate a range of topics related to tasks, including attitudes to TBLT, options for language input in the pre-task phase, the communicativeness of ostensibly task-based classrooms, the value of risk-taking in TBLT, the quality of computer mediated task-based interaction, and the effectiveness of tasks for intercultural language learning.

In the first article, Michael Hood, James Elwood and Joseph Falout survey the attitudes of Japanese tertiary students to communicative and task-based methodologies. As they point out, much of the recent research which highlights resistance towards and constraints on uptake of communicative methodology by teachers fails to take into consideration students' perceptions and preferences. To address this gap, the authors carried out a large-scale survey of student attitudes towards TBLT. They found that overall, students were receptive to TBLT and to the general characteristics of communicative pedagogy. They further argue that questions as to the appropriateness of such methodologies for Japan need to be re-evaluated in the light of these findings.

Also investigating attitudes to TBLT, David Carless presents a qualitative study involving interviews with secondary school teachers and teacher educators in Hong Kong to seeks their views on and preferences for TBLT versus PPP (Presentation, 
Practice, Performance). Carless found a general preference for PPP among the teachers but for TBLT among the teacher educators. This disjoint echoes the divide between the intended and enacted curriculum discussed above and outlined in Fig 1. The data and discussion presented offer important insights into why these teachers tended to resist adopting TBLT. In response, Carless makes some tentative suggestions for a rapprochement between TBLT and PPP as well as calling for research into how TBLT can be more effectively implemented in teacher education. Such research may offers a way to bring the intended and enacted curriculum in Hong Kong closer together.

Jasmine Luk, in the second of three studies situated in Hong Kong, shifts the focus onto implementation of TBLT, a focus that the remaining five articles share. Luk uses a case-study approach to examine the way Anita, a teacher in a Honk Kong school, implemented the pre-task phase of a task-base lesson. In focusing on how Anita perceived and addressed the learners' language needs, Luk highlights a tendency to see the language preparation for a task as essentially code-based and focused on lexical items and grammatical rules. Luk concludes by proposing a genre-based framework that encourages teachers to embrace a more discourse-oriented view of language knowledge implied by a task performance.

The fourth contributor, Gertrude Tinker Sachs, discusses the experiences of Hong Kong primary school teachers and learners involved in a three-year cooperative learning research project in which TBLT played an important role. The author focuses on the risk-taking associated with participating in this teaching innovation, and, as with other articles in this issue, allows the voices of both teachers and learners to emerge from the discussion.

Chun-Rao Deng and David Carless use Littlewood's 2004 continuum of communicativeness of activities to analyse twelve lessons conducted by Rose, a primary teacher in Guangdong, China. Material from a series of interviews with Rose supplement the observational data. The authors use this case study to highlight a recurring theme in this collection, that is, the distance between the enacted curriculum as seem here in Rose's mostly non-communicative lessons, and the intended curriculum which, in this case, strongly advocates TBLT.

Nita Alwi and Rebecca Adams investigate the use of communication strategies by Malaysian tertiary students engaged in tasks in a virtual learning environment (synchronous computer-mediated communication or SCMC). Their study focuses on 
the nature of interaction between learners engaged in task performance. As such it draws on the long tradition of studying classroom interaction in order to identify language acquisition potentialities that can be traced (at least) to the work of Evelyn Hatch (1978) and Michael Long (1983). The results of the study point to the richness of the communicative environment provided by SCMC and to the distinctive characteristics of task-based discourse generated in such environments.

Eriko Ishii's study provides a fitting conclusion to this collection through its focus on measuring the effect of task-based instruction on student learning. Ishii's research compares the effects of two tasks on attitudinal dimensions of the intercultural competence of Japanese high-school English language students. Because the main focus of this study is intercultural language leaning, it represents a unique synthesis of two quite distinct fields of research and scholarship within the field of applied linguistics - those of TBLT and intercultural education.

Our title for this introduction is 'TBLT in Asia: Constraints and Opportunities'. Constraints can be seen in the recurring theme of resistance by teachers to TBLT innovations and in the situational and cultural barriers to implementing task-based teaching reported by, among others, Carless and Luk. But even where constraints are highlighted, the first hand insights from teachers and learners involved in task-based innovations and discussed in these articles offer an informed basis on which to address problems and recalibrate strategies for implementing TBLT. Furthermore, we see cause for optimism in the openness of students to task-based methodology (Hood, et al), the richness of the interactions generated in tasks performed via SCMC (Alwi and Adams), and in the positive effects of task-based intercultural language learning (Ishii). These and other findings discussed in the collection point to possibilities and opportunities for TBLT in Asia and beyond. 


\section{References}

Adamson, B. \& Davison, C. (2003). Innovation in English language teaching in Hong Kong primary schools: One step forward, two steps sideways? Prospect, 18(1), 27-41.

Butler, Y.G. (2005). Comparative perspectives toward communicative activities among elementary school teachers in South Korea, Japan and Taiwan, Language Teaching Research, 9, 423-446.

Bygate, M., Skehan, P., \& Swain, M. (Eds.). (2001). Researching pedagogical tasks: Second language learning, teaching, and testing. Harlow: Pearson Education.

Carless, D. (2004). Issues in teachers' reinterpretation of a task-based innovation in primary schools. TESOL Quarterly, 38, 639-662.

Carless, D. (2007). The suitability of task-based approaches for secondary schools: Perspectives from Hong Kong. System, 35, 595-608.

Chang, B. (2004). A case study of native English-speaking teachers' understanding of EFL contexts in Korea. Pan-Pacific Association of Applied Linguistics, 8, 119-135.

Clark, J., Lo, Y.C., Hui, M.F., Kam, M., Carless, D. \& Wong, P.M. (1999). An investigation into the development and implementation of the TOC initiative with special reference to professional competencies, professional development and resources: Final report. Hong Kong: Hong Kong Institute of Education.

Chao, J.C. \& Wu, A.M. (2008). A Study of Task-based Learning and Teaching in a Large EFL Class. Saarbruken: Verlag Dr. Muller.

Chow, A.K.W. \& Mok-Cheung, A.H.M. (2004). English language teaching in Hong Kong SAR: Tradition, transition, and transformation. In H.W.Kam \& R.Y.L. Wong (Eds.) Language policies and language education: The impact in east Asian countries in the next decade. Singapore: Times Academic Press.

Cortazzi, M., \& Jin, L. (1996b). English teaching and learning in China. Language Teaching, 29(2), 61-80.

Eguchi, M. \& Eguchi, K. (2006). The limited effect of PBL on EFL learners: A case study of English magazine projects. Asian EFL Journal, 8 (3), 207-225.

Ellis, R. (Ed.). (2005). Planning and task performance in a second language. Amsterdam: John Benjamins.

Finch, A. (2001). A formative evaluation of a task-based conversation English program. The PAC Journal, 1(1), 125-146. 
Gorush, G. J. (2000). EFL educational policies and educational cultures: Influences on teachers' approval of communicative activities. TESOL Quarterly, 34, 675-710.

Hsu, Y.J. (2007). Elementary School EFL Students' Learning Style Preferences and Strategy Use and their Relationship with the Students' English Learning Achievement. Masters Thesis, Taiwan: Providence University.

Hu, G. (2002). Recent important developments in secondary English-language teaching in the People's Republic of China. Language, Culture and Curriculum, 15, 30-49.

Hu, G. (2005). English language education in China: Policies, progress, and problems. Language Policy, 4, 5-24.

Jeon, I.J. (2006). EFL teachers' perception of task-based language teaching: With a focus on Korean secondary classroom practice. Asian EFL Journal, 8, 192-206.

Lee, S.M. (2005). The pros and cons of task-based instruction in elementary English classes. English Teaching, 60, 185-205.

Li, D.F. (1998). 'It's always more difficult than you plan and imagine': Teachers' perceived difficulties in introducing the communicative approach in South Korea. TESOL Quarterly, 32, 677-703.

Littlewood, W. (2007). Communicative and task-based language teaching in East Asian classrooms. Language Teaching, 40, 243-249.

Long, M. H. (1996). The role of the linguistic environment in second language acquisition. In W.C. Ritchie \& T.K. Bhatia (Eds.) Handbook of Second Language Acquisition (p. 413-68). New York: Academic Press.

McDonough, K., \& Chaikitmongkol, W. (2007). Teachers' and Learners' Reactions to a Task-Based EFL Course in Thailand. TESOL Quarterly, 41, 107-132.

Nunan, D. (2004). Task-based language teaching. Cambridge: Cambridge University Press.

O’Dwyer, F. (2009). Supplementing a task-based curriculum with the European Language Portfolio. The Language Teacher, 33(3), 15-20.

Samuda, V. \& Bygate, M. (2008). Tasks in second language learning. Houndsmills, Hampshire: Palgrave Macmillan.

Shim, R. (2001). Teaching English through movies: How to do it the communicative way. STEM Journal, 2(2), 129-154.

Shim, R. \& Baik, M. (2000). South and North Korea. In H.W.Kam \& R.Y.L. Wong (Eds.) Language policies and language education: The impact in east Asian countries in the next decade. Singapore: Times Academic Press. 
Skehan, P. (1998). A Cognitive Approach to Language Learning. Oxford: Oxford University Press.

Sung, C.M. (2005). An action research for communicative English teaching implemented in an elementary school: An example of fourth graders. Journal of National Taipei University of Education, 18, 267-296.

Tinker-Sachs, G. (2007). The challenges of adopting and adapting task-based cooperative teaching and learning in an EFL context. In K. van den Branden, K. van Gorp \& M. Verhelst (2007). Tasks in action: Task-based language education from a classroom-based perspective (p. 253-264). Newcastle: Cambridge Scholars Press.

Van den Branden, K. (Ed.). (2006). Task-based language education: From theory to practice. Cambridge: Cambridge University Press.

Weaver, C. (2007). Willingness to communicate: A mediating factor in the interaction between learners and tasks. In K. van den Branden, K. van Gorp \& M. Verhelst (2007). Tasks in action: Task-based language education from a classroombased perspective (p. 159-194). Newcastle: Cambridge Scholars Press.

Willis, D., \& Willis, J. (2007). Doing task-based teaching. Oxford: Oxford University Press.

Zhang, E.Y. (2007). TBLT innovation in primary school English language teaching in mainland China. In K. van den Branden, K. van Gorp \& M. Verhelst (2007). Tasks in action: Task-based language education from a classroom-based perspective (p. 68-91). Newcastle: Cambridge Scholars Press. 